doi: 10.32620/oikit.2021.91.12

УДК 004.896

Ю. М. Толкунова ${ }^{1}$, Д. О. Подколзіна ${ }^{2}$

\title{
Дослідження алгоритмів навігації та картографії для безпіло- тного літального апарату
}

\author{
${ }^{1}$ Національний аерокосмічний університет ім. М. Є. Жуковського \\ "Харківський авіаційний інститут» \\ ${ }^{2}$ Південний феедеральний університет
}

\begin{abstract}
Розглядаються методи навігації безпілотного літального апарату (БПЛА). Основну увагу зосереджено на методах навігації, які зводять діяльність оператора до постановки поточних завдань та спостереження за функціонуванням БПЛА. БПЛА повинен самостійно оцінювати навколишню обстановку і планувати свій шлях, в тому числі і при наявності інших рухомих об'єктів. Рішення задач управління і навігації БПЛА без пульта, істотно полегшує завдання оператора, але вимагає розробки системи управління БПЛА. До числа таких завдань відноситься і задача автоматичного повернення БПЛА при втраті зв'язку з оператором, рішення якої підвищує надійність навігаційної системи. Зміна характеру діяльності оператора, який тепер не керує безпосередньо рухами БПЛА, призводить до зміни характеру системи управління. Одним із шляхів вирішення цього завдання $є$ застосування оптичної навігаційної системи. Проведено аналіз методів та алгоритмів оптичної навігації безпілотного літального апарату: алгоритмів локальної навігації та картографії, кореляційно-екстремальних навігаційних методів та методів візуальної одометрії. Розглянуто переваги та недоліки методів оптичної навігації. Використання методів візуальної одометрії має переваги в порівнянні з іншими методами але має і недоліки пов'язані 3 накопичення помилки в ході роботи методу. Різновиди алгоритмів одночасної локалізації і побудови карти (Simultaneous localization and mapping, SLAM), які ґрунтуються на використанні камер називаються visual SLAM. Проведено аналіз методів visual SLAM та візуальної одометрії. Гібридні методи SLAM дозволяють вирішити проблему накопичення помилки.

Проаналізовано використання БПЛА для дослідження геологічних процесів берегової лінії водосховищ і морів. Розглянуто переваги застосування алгоритмів SLAM для моніторингу стану берегової лінії. Зроблено висновки, що використання алгоритмів SLAM для оцінки густоти ерозійної мережі берегової лінії водосховищ і морів дозволяє отримати знімки без геометричних спотворень, оптична навігаційна система на основі цих алгоритмів істотно полегшує завдання оператора, дозволить повернути БПЛА при втраті зв'язку з оператором.
\end{abstract}

Ключові слова: оптична система навігації, безпілотний літальний апарат, алгоритми локальної навігації та картографії, моніторинг стану берегів.

\section{Вступ}

Постановка задачі. Визначення положення і орієнтації мобільного об'єкта в просторі одна з найскладніших задач в системі управління БПЛА. Складність обумовлена тим, що вимоги до габаритних та масових характеристик БПЛА дозволяють використовувати мінімальних набір пристроїв для забезпечення автономного польоту, але при цьому повинна забезпечуватись якомога вища точність. Тому актуальним $є$ дослідження алгоритмів навігації та розробка системи навігації і орієнтації для БПЛА яка б задовольняла перерахованим вище вимогам.

Перспективним напрямком $€$ інтегрування з основною навігаційною системою допоміжних систем. Допоміжною може бути оптична навігаційна система, 
яка визначає положення шляхом візуальної одометрії, одночасної локалізації та побудови карти або заснована на кореляційно-екстремальних методах.

На теперішній час БПЛА застосовується в різних область людської діяльності. Однією з задач використання БПЛА $є$ дослідження геологічних процесів берегової лінії водосховищ і морів. Керування БПЛА за допомогою оператора при охопленні значних територій вимагає вдосконалення системи контролю та керування БПЛА, також існує проблема пов'язана з сильною дисторсією, що виражається в спотворенні отриманих кадрів. Тому актуальною задачею є застосування алгоритмів SLAM для дослідження густоти ерозійної мережі території берегової зони водосховищ і морів.

Мета роботи. Дослідження алгоритмів та методів оптичної навігації, а також формулювання рекомендацій щодо їх використання та комбінування для компенсації недоліків кожного з них. Аналіз застосування алгоритмів SLAM для дослідження геологічних процесів берегової лінії водосховищ і морів.

\section{1 Методи оптичної навігації}

Візуальна одометрія - метод оцінки лінійного і кутового зміщення робота за допомогою аналізу послідовності зображень, знятих встановленою на ньому камерою [5]. Стандартний алгоритм візуальної одометрії:

1) отримання зображення з камери;

2) корекція зображення;

3) детектування ключових точок зображення;

4) перевірка векторів оптичного потоку на потенційні помилки;

5) визначення руху камери з оптичного потоку;

6) періодичне оновлення набору ключових точок для відстеження.

Позиціонування БПЛА по оптичному сенсору зводиться до визначення набору точок, що виділяються на зображенні. Основу візуальної одометрії становить відстеження переміщень таких точок від кадру до кадру для розрахунку зміни положення БПЛА щодо навколишнього простору. До недоліків візуальної одометрії слід віднести накопичення помилки в ході роботи методу.

Під кореляційно-екстремальними системами розуміють системи обробки інформації, представленої у вигляді реалізацій випадкових фрункцій (полів), призначених для визначення координат руху або інших цілей. Для цілей навігації, наведення і радіолокації подібні системи отримали назву кореляційноекстремальних навігаційних систем (КЕНС) [1]. Під час першого польоту фіксується зображення підстильної місцевості. Воно служить еталоном для наступних польотів, при яких керування літаком проводиться так, щоб еталонне і поточне зображення збігалися. У цьому полягає ідея управління рухом літального апарату за заданим курсом з використанням карт місцевості [2].

КЄНС притаманні суттєві недоліки:

- вони потребують оновлення опису зображень (знімків поверхонь), тобто підтримки знімків в актуальному стані. Тому виникають складнощі застосування цього методу у випадках зміни ландшафту, наприклад, внаслідок бойових дій. До того ж зображення підстильної місцевості треба отримувати заздалегідь;

- зіставлення зображень між якими існують неузгодженість за масштабом потребує складної попередньої обробки;

- зміна точки огляду призводить до великих ракурсних спотворень на зображеннях з гористими областями. 
Метод одночасної локалізації і побудови карти (Simultaneous localization and mapping, SLAM) - це розрахункова схема побудови та оновлення карти невідомого навколишнього середовища з одночасним відстеженням місцезнаходження робота в ії̈ межах. Вхідною інформацією для рішення даного завдання $\epsilon$ дані, одержані з різних мультисенсорних датчиків. У певні дискретні моменти часу датчики сканують навколишнє середовище і відправляють отримані дані у вигляді кадрів для подальшої обробки та аналізу. Таким чином, кадр є системою відліку часу в системі SLAM. Вихідною інформацією для даної задачі $є$ реконструкція сцени і траєкторія руху мобільного робота. Застосування SLAM має ряд технічних труднощів пов'язаних з точністю калібрування відеокамер, не чутливістю до змін в середовищі та інші, в залежності від різновиду алгоритму $[3,4]$.

\section{2 Порівняння способів навігації}

На основі аналізу різних способів оптичної навігації можна скласти порівняльну таблицю і виділити переваги і недоліки кожного способу. В таблиці 1 наведено порівняння основних методів, що застосовуються сьогодні для вирішення завдань оптичної навігації БПЛА та GPS навігації. Тут показані переваги «+» і недоліки «-» розглянутих способів навігації.

\section{Порівняння способів навігації БПЛА}

Таблиця 1

\begin{tabular}{|c|c|c|c|c|c|c|}
\hline & \multicolumn{6}{|c|}{ Характеристики способів навігації } \\
\cline { 2 - 7 } & $\begin{array}{c}\text { Розмір } \\
\text { Спсіб на- } \\
\text { вігації } \\
\text { рерито- } \\
\text { обме- } \\
\text { жений }\end{array}$ & $\begin{array}{c}\text { Висока } \\
\text { точність } \\
\text { на ко- } \\
\text { ротких } \\
\text { траєк- } \\
\text { торіях }\end{array}$ & $\begin{array}{c}\text { Інваріан- } \\
\text { тна до } \\
\text { змін в } \\
\text { середо- } \\
\text { вищі }\end{array}$ & $\begin{array}{c}\text { Не нако- } \\
\text { пичує } \\
\text { помилку }\end{array}$ & $\begin{array}{c}\text { Не потре- } \\
\text { бує стаці- } \\
\text { онарних } \\
\text { об'єктів }\end{array}$ & $\begin{array}{c}\text { Робота в } \\
\text { умовах 3 } \\
\text { високим } \\
\text { вмістом } \\
\text { переш- } \\
\text { код }\end{array}$ \\
\hline GPS & + & - & + & + & + & - \\
\hline SLAM & - & $+/-$ & - & + & - & + \\
\hline KEHC & - & + & - & + & + & + \\
\hline $\begin{array}{c}\text { Візуальна } \\
\text { одометрія }\end{array}$ & + & + & + & - & + & + \\
\hline
\end{tabular}

Метод візуальної одометрії не залежить від радіоперешкод, має високу точність, не залежить від розташування додаткових стаціонарних об'єктів але має і недоліки пов'язані з накопичення помилки в ході роботи методу [12-15]. Проблема накопичення помилки вирішена в деяких алгоритмах SLAM.

\section{SLAM та візуальна одометрія}

Розглянемо найбільш поширені різновиди алгоритмів monoSLAM з використанням візуальної одометрії.

3.1. Алгоритм SLAM з розширеним фольтром Калмана (extended Kalman filter, EKF). EKF - це один із найбільш поширених методів рішення завдань SLAM [7]. Він дозволяє не тільки уточнити оцінку положення БПЛА на карті, але і положення всіх виявлених орієнтирів. Стан фрільтра зберігається в двох змінних: 
1. $\mu_{t}=\left[s_{t}, \theta_{1}, \theta_{2}, \ldots, \theta_{N}\right]$ - вектор математичного очікування, де $s_{t}$ - положення робота, $\theta_{N}$ - положення орієнтирів.

2. $\sum u_{t}-$ матриця коваріації, що містить перехресні коваріації всіх елементів $u_{t}$.

3 етапами роботи фрільтру можна ознайомитись в $[7,8]$. Серед недоліків EKF можна виділити:

- проблему з повторним виявленням орієнтирів; реження;

- накопичення помилки, в результаті лінеаризації моделей руху і спосте-

- неможливість застосування на місцевості з великою кількістю орієнтирів, зважаючи на складність обчислення матриці коваріації.

Деякі з цих проблем вирішуються модифікаціями методу [9].

3.2 Алгоритм LSD-SLAM (Large-Scale Direct Monocular SLAM). В цьому алгоритмі паралельно працюють три процедури: трекінг, побудова карти і оптимізація карти. Компонент трекінгу оцінює стан кожного нового кадру щодо поточного ключового кадру. Компонент побудови карти обробляє кадри з відомим положенням, або роблячи очищення карти кадру, або створюючи новий ключовий кадр. Компонент оптимізації карти займається пошуком циклів в графрі ключових кадрів і усуненням ефекту плаваючого масштабу. Оптимізація дозволяє запобігти накопиченню помилок у відстеженні місця розташування і підтримує точність побудови карти навколишнього середовища [6].

3.3 Алгоритм ORB-SLAM. Даний алгоритм заснований на детекторі ключових точок ORB [11]. Висока швидкість детектора ORB дозволяє методу працювати в реальному часі в умовах обмежених обчислювальних ресурсів. Робота алгоритму розділена на три основні потоки. Tracking - відстеження кадрів. Даний потік приблизно визначає поточний стан камери шляхом пошуку схожого кадру в локальній карті і зіставлення ключових точок з знайденим кадром. Local Mapping - виконує побудову карти поблизу поточного положення камери і оптимізує карту. Loop Closing - алгоритм замикання циклів, який шукає і об'єднує схожі кадри. Крім локальної оптимізації, ORB SLAM виконує глобальну оптимізацію карти, яка дозволяє зменшити накопичену помилку з урахуванням знайдених замикань циклів. В рамках ORB-SLAM існує велика кількість реалізацій окремих частин алгоритму і реалізована система вибору методу, який більше підходить до даної конкретної ситуації.

Проаналізувавши алгоритми SLAM зрозуміло, що більшої популярності набирають сучасні методи, позбавлені недоліків «класичних» розширеного фільтра Калмана. 3'являється безліч гібридних методів, які суміщають в собі тільки кращі риси попередніх алгоритмів.

\section{SLAM для дослідження просторового геоекологічного аналізу бе- регової зони водосховищ і морів}

На сьогоднішній день для дослідження просторового геоекологічного аналізу берегової зони водосховищ і морів використовують знімки отримані за допомого БПЛА або супутникові зображення. Перевагою даних, одержуваних 3 використанням БПЛА, в порівнянні з супутниковими зображеннями $є$ можливість підхмарної зйомки [16].

Дослідження [17] показали, що використання БПЛА для моніторингу зміни положення бровки берегових обривів дозволяє детально описати місця фрактич- 
них деформацій берега, встановити кордони і форми ділянок, зруйнованих в результаті прояву екзогенних геологічних процесів, включаючи ділянки берега, не обладнані пунктами спостереження мережі Державного моніторингу водоохоронної зони. В статті [18] підкреслюється, що оптична система БПЛА характеризується сильною дисторсією, що виражається в спотворенні отриманих кадрів. Тому для дослідження просторового геоекологічного аналізу берегової зони водосховищ і морів за допомогою БПЛА запропоновано використовувати алгоритми SLAM. Алгоритми SLAM мають математичних апарат для обробки знімків для запобігання дисторсії. Ще однією перевагою алгоритмів SLAM $є$ можливість керування БПЛА без оператора або полегшення роботи оператора та підвищення контролю за БПЛА. Система управління БПЛА на основі оптичної навігації дозволяє обминати перешкоди та автоматично повертати БПЛА при втраті зв'язку з оператором.

Проаналізувавши різні підходи до реалізації монокулярного SLAM можна зробити висновок, що найбільш перспективними $є$ алгоритми LSD SLAM та ORB-SLAM. B результаті порівняння цих алгоритмів отримали:

- алгоритм ORB SLAM підтримує роботу з монокулярною, стерео і RGB-D камерами, LSD SLAM підтримує роботу тільки з монокулярною камерою;

- LSD SLAM та ORB-SLAM мають відкритий вихідний код;

- LSD SLAM здатний будувати щільну карту навколишнього середовища, яку можна використовувати для дослідження геологічних процесів;

- алгоритм LSD SLAM менш продуктивний в порівнянні з ORB-SLAM, вимагає значних обчислювальних ресурсів але зберігає зображення цілком, а не тільки ключові точки [10].

Перспективним напрямком вдосконалення проаналізованих алгоритмів SLAM $€$ адаптації обраного алгоритму візуальної навігації для використання 3 багатоспрямованими датчиками (катадіоптричними камерами або камерами 3 ширококутною лінзою). У статтях $[19,20]$ автори адаптували алгоритми SLAM 3 розширеним фрільтром Калмана під використання багатоспрямованих датчиків. Проведені експерименти довели ефективність такого підходу при використанні його на невідомій місцевості.

\section{Висновки}

В статті проаналізовано методи оптичної навігації БПЛА. Проведено порівняння оптичної навігаційної системи, яка визначає положення шляхом візуальної одометрії, одночасної локалізації та побудови карти (SLAM) або заснована на кореляційно-екстремальних методах. Визначено, що алгоритм одночасної локалізації та побудови карти є універсальним рішенням для навігації БПЛА.

Розглянуто можливості використання БПЛА для моніторинг стану берегів. Аналіз досліджень виявив перспективність застосування БПЛА в дослідженні ерозійної форми рельєфу берегової лінії. Застосування методів SLAM для автоматизації процесу керування та навігації БПЛА значно полегшить роботу оператора при дослідженні територій берегової лінії, а також спростить обробку отриманих знімків. 


\section{Список літератури}

1. Сырямкин, В.И., Шидловский, В.С. Корреляционно-экстремальные радионавигационные системы [Текст] / В.И. Сырямкин, В.С. Шидловский. - Томск: Изд-во Том. ун-та, 2010. - 316 с.

2. Баклицкий, В.К. Корреляционно-экстремальные методы навигации и наведения [Текст] / В.К. Баклицкий. - Тверь: ТО «Книжный клуб», 2009. - 360 с.

3. Dorian, G.-L. Marta, S., Juan, D. T., Montiel, J.M.M. Real-time monocular object SLAM. Robotics and Autonomous Systems 2016, 75, pp. 435-449.

4. Folkesson, J., Leederkerken, J., Williams, R., Patrikalakis, A., Leonard, J.A. A Feature Based Navigation System for an Autonomous Underwater Robot. Proceedings of the sixth edition of Field and Service Robotics, Chamonix, France, 9-12 July 2007; Laugier C., Siegwart R. Eds; Springer Tracts in Advanced Robotics Springer: Berlin, Germany, 2008, pp.105-114.

5. Nist'er, D., Naroditsky, O., Bergen, J. Visual odometry for ground vehicle applications. Journal of Field Robotics. - 2006. - Vol. 23 (1), pp. 3-20.

6. Engel J., Schops T., Cremers D. LSD-SLAM: Large-Scale Direct Monocular SLAM. European Conference on Computer Vision, Springer, Vol. 8690, 2014, pp.834-849.

7. Diosi, A., Kleeman, L., Laser scan matching in polar coordinates with application to SLAM. Proceedings of IEEE/RSJ International Conference on Intelligent Robots and Systems (IROS 2005). - 2005, pp. 3317- 3322.

8. Riisgaard, S., Blas, M. A tutorial approach to simultaneous localization and mapping. Massachusetts Institute of Technology, Mobile Robotics course materials. $-2012.127 \mathrm{p}$.

9. Кэ., Кэ. Гэн. Автономная система управления полетом квадрокоптера с возможностью облета препятствий и комплексной навигацией [Текст]: дис. ... кта техн. наук: 05.13.01; защищена 2017 / Ген Кэ Кэ - М., 2017. - 158 с.

10. Панков, В.Д., Шульга, В.А.. Сравнение алгоритмов локализации ORBSLAM и LSD-SLAM [Текст] //«Молодой учёный». № 27 (213). - М., 2018. - с. 1618.

11. Caballero, F., Merino, L., Ferruz, J., Ollero, A. Vision-Based Odometry and SLAM for Medium and High Altitude Flying UAVs. Journal of Intelligent Robotics System. - 2009. - Vol. 54., Issue 1-3, pp. 137 - 161.

12. Bobkov, V. A., Ron'shin, Yu. I., Kudryashov, A. P., Mashentsev, V. Yu.. 3D SLAM from Stereoimages. Programming and Computer Software, 2014, Vol. 40, No. 4, 2014, pp. 159-165.

13. Olson E. Recognizing places using spectrally clustered local matches. Robotics and Autonomous Systems, vol. 57, No. 12, December 2009, pp. 1157-1172.

14. Williams, B., Cummins M., Neira J., Newman P., Reid I., Tardos J. A comparison of loop closing techniques in monocular SLAM Robotics and Autonomous Systems 57 (12), pp. 1188-1197.

15. Cadena, C., Galvez, D., Ramos, F., Tardos, J., Neira, J. Robust place recognition with stereo cameras. In Proc. IEEE / RJS Int. Conference on Intelligent Robots and Systems. Taipei, Taiwan, 2010, pp.5182-5189.

16. Савин, И.Ю., Вернюк, Ю.И., Фараслис, И. Возможности использования беспилотных летательных аппаратов для оперативного мониторинга продуктивности почв // Бюллетень Почвенного института им. В.В. Докучаева. - 2015. Вып. 80. - С. 95-105. 
17. Скрипка, Г.И., Ивлиева, О.В., Беспалова, Л.А., Филатов, А.А., Сапрыгин, В.В. Мониторинг опасных береговых процессов Цимлянского водохранилища с использованием ГИС-технологий // Географические информационные системы и технологии. - 2020. - Том 26. №2 - С. 253-263.

18. Воскресенский, И.С., Сучилин, А.А., Ушакова, Л.А., Шафроростов, В.М., Энтин, А.Л. Применение БПЛА для мониторинга оползневых и эрозийных процессов (на примере центра Русской равнины) // Материалы Всероссийской научно-практической конференции. - Иркутск: Издательство Института географиии им. В.Б. Сочавы СО РАН, - 2018. - С. 42-47.

19. Rituerto, A., Puig, L., Guerrero, J. Visual SLAM with an omnidirectional camera. 2010 20th International Conference on Pattern Recognition CPR 2010, 2326 August 2010, Istanbul, Turkey: proceedings, pp. 348-351.

20. Guofeng, Tong, Zizhang, Wu, NingLong, Weng, Wenbo, Hou. An Omnidirectional vSLAM based on spherical camera model and 3D modeling. Proceedings of the 10th World Congress on Intelligent Control and Automation, Beijing, China, 2012, pp. 4551-4556.

\section{References}

1. Syrjamkin, V.I., Shidlovskij, V.S. Korreljacionno-jekstremal'nye radionavigacionnye sistemy [Correlation-extreme radionavigation systems]. Tomsk: Izd-vo Tom. un-ta, 2010. p. 316.

2. Baklickij, V.K. Korreljacionno-jekstremal'nye metody navigacii i navedenija [Correlation-extreme methods of navigation and guidance]. Tver': TO «Knizhnyj klub», 2009. p. 360.

3. Dorian, G.-L. Marta, S., Juan, D. T., Montiel, J.M.M. Real-time monocular object SLAM. Robotics and Autonomous Systems 2016, 75, pp. 435-449.

4. Folkesson, J., Leederkerken, J., Williams, R., Patrikalakis, A., Leonard, J.A. A Feature Based Navigation System for an Autonomous Underwater Robot. Proceedings of the sixth edition of Field and Service Robotics, Chamonix, France, 9-12 July 2007; Laugier C., Siegwart R. Eds; Springer Tracts in Advanced Robotics Springer: Berlin, Germany, 2008, pp.105-114.

5. Nist'er, D., Naroditsky, O., Bergen, J. Visual odometry for ground vehicle applications. Journal of Field Robotics. 2006. Vol. 23 (1), pp. 3-20.

6. Engel J., Schops T., Cremers D. LSD-SLAM: Large-Scale Direct Monocular SLAM. European Conference on Computer Vision, Springer, Vol. 8690, 2014, pp.834-849.

7. Diosi, A., Kleeman, L., Laser scan matching in polar coordinates with application to SLAM. Proceedings of IEEE/RSJ International Conference on Intelligent Robots and Systems (IROS 2005). 2005, pp. 3317-3322.

8. Riisgaard, S., Blas, M. A tutorial approach to simultaneous localization and mapping. Massachusetts Institute of Technology, Mobile Robotics course materials. 2012. 127 p.

9. Kje., Kje. Gjen. Avtonomnaja sistema upravlenija poletom kvadrokoptera s vozmozhnost'ju obleta prepjatstvij i kompleksnoj navigaciej [Autonomous flight control system of a quadcopter with the ability to fly around obstacles and integrated navigation. K-ta tehn. sci. diss.]. Moscow, 2017. 158 p.

10. Pankov, V.D., Shul'ga, V.A.. Sravnenie algoritmov lokalizacii ORB-SLAM i LSD-SLAM [Comparison of localization algorithms ORB-SLAM and LSD-SLAM]. Molodoj uchjonyj. № 27 (213), 2018. - pp. 16-18. 
11. Caballero, F., Merino, L., Ferruz, J., Ollero, A. Vision-Based Odometry and SLAM for Medium and High Altitude Flying UAVs. Journal of Intelligent Robotics System. 2009. Vol. 54., Issue 1-3, pp. 137-161.

12. Bobkov, V. A., Ron'shin, Yu. I., Kudryashov, A. P., Mashentsev, V. Yu.. 3D SLAM from Stereoimages. Programming and Computer Software, 2014, Vol. 40, No. 4, 2014, pp. 159-165.

13. Olson E. Recognizing places using spectrally clustered local matches. Robotics and Autonomous Systems, vol. 57, No. 12, December 2009, pp. 1157-1172.

14. Williams, B., Cummins M., Neira J., Newman P., Reid I., Tardos J. A comparison of loop closing techniques in monocular SLAM Robotics and Autonomous Systems 57 (12), pp. 1188-1197.

15. Cadena, C., Galvez, D., Ramos, F., Tardos, J., Neira, J. Robust place recognition with stereo cameras. In Proc. IEEE / RJS Int. Conference on Intelligent Robots and Systems. Taipei, Taiwan, 2010, pp. 5182-5189.

16. Savin, I.Ju., Vernjuk, Ju.I., Faraslis, I. Vozmozhnosti ispol'zovanija bespilotnyh letatel'nyh apparatov dlja operativnogo monitoringa produktivnosti pochv [Possibilities of using unmanned aerial vehicles for operational monitoring of soil productivity]. Bjulleten' Pochvennogo instituta im. V.V. Dokuchaeva. 2015. Vyp. 80. - pp. 95-105.

17. Skripka, G.I., Ivlieva, O.V., Bespalova, L.A., Filatov, A.A., Saprygin, V.V. Monitoring opasnyh beregovyh processov Cimljanskogo vodohranilishha $s$ ispol'zovaniem GIS-tehnologij [Monitoring of hazardous coastal processes of the Tsimlyansk reservoir using GIS-technologies]. Geograficheskie informacionnye sistemy i tehnologii. 2020. Tom 26. №2 pp. 253-263.

18. Voskresenskij, I.S., Suchilin, A.A., Ushakova, L.A., Shaforostov, V.M., Jentin, A.L. Primenenie BPLA dlja monitoringa opolznevyh i jerozijnyh processov (na primere centra Russkoj ravniny) [The use of UAVs for monitoring landslide and erosion processes (on the example of the center of the Russian Plain)] Materialy Vserossijskoj nauchno-prakticheskoj konferencii. [Izdatel'stvo Instituta geografii im. V.B. Sochavy SO RAN]. - Irkutsk, 2018, - pp. $42-47$ (In Russian).

19. Rituerto, A., Puig, L., Guerrero, J. Visual SLAM with an omnidirectional camera. 2010 20th International Conference on Pattern Recognition CPR 2010, 2326 August 2010, Istanbul, Turkey: proceedings, pp. 348-351.

20. Guofeng, Tong, Zizhang, Wu, NingLong, Weng, Wenbo, Hou. An Omnidirectional VSLAM based on spherical camera model and 3D modeling. Proceedings of the 10th World Congress on Intelligent Control and Automation, Beijing, China, 2012, pp. 4551-4556.

Надійшла до редакції 10.04.2021, розглянута на редколегії 10.04.2021

\section{Исследование алгоритмов навигации и картографии для бес- пилотного летательного аппарата}

Рассматриваются методы навигации беспилотного летательного аппарата (БПЛА). Основное внимание сосредоточено на методах навигации, которые сводят деятельность оператора к постановке текущей задачи и наблюдению за функционированием БПЛА. БПЛА должен самостоятельно оценивать окружающую обстановку и планировать свой путь, в том числе и при наличии других движущихся объектов. Решение задач управления и навигации БПЛА без пуль- 
та, существенно облегчает задачу оператора, но требует разработки системы управления БПЛА. К числу таких задач относитесь и задача автоматического возврата БПЛА при потере связи с оператором, решение которой повышает надежность навигационной системы. Изменение характера деятельности оператора, который теперь не управляет непосредственно движениями БПЛА, приводит к изменению характера системы управления. Одним из путей решения этой задачи является применение оптической навигационной системы. Проведен анализ методов и алгоритмов оптической навигации беспилотного летательного аппарата: алгоритмов локальной навигации и картографии, корреляционно-экстремальных навигационных методов и методов визуальной одометрии. Рассмотрены преимущества и недостатки методов оптической навигации. Использование методов визуальной одометрии имеет преимущества по сравнению с другими методами, но имеет и недостатки связаны с накопления ошибки в ходе работы метода. Разновидности алгоритмов одновременной локализации и построения карты (Simultaneous location and mapping, SLAM), основанные на использовании камер называются visual SLAM. Проведен анализ методов visual SLAM и визуальной одометрии. Гибридные методы SLAM позволяют решить проблему накопления ошибки.

Проанализировано использование БПЛА для исследования геологических процессов береговой линии водохранилищ и морей. Рассмотрены преимущества применения алгоритмов SLAM для мониторинга состояния береговой линии. Сделаны выводы, что использование алгоритмов SLAM для оценки густоты эрозионной сети береговой линии водохранилищ и морей позволяет получить снимки без геометрических искажений, оптическая навигационная система на основе этих алгоритмов существенно облегчает задачу оператора, позволит вернуть БПЛА при потере связи с оператором.

Ключевые слова: оптическая система навигации, беспилотный летательный аппарат, алгоритмы локальной навигации и картографии, мониторинг состояния берегов.

\section{Research of navigation and cartography algorithms for un- manned aerial vehicle}

The methods of navigation of an unmanned aerial vehicle (UAV) are considered. The main focus is on navigation methods that reduce the operator's activities to setting the current task and monitoring the operation of the UAV. The UAV must independently assess the environment and plan its path, including in the presence of other moving objects. The solution of control and navigation tasks for UAVs without a remote control significantly facilitates the operator's task, but requires the development of a UAV control system. These tasks include the task of automatically returning the UAV in case of loss of communication with the operator, the solution of which increases the reliability of the navigation system. The change in the nature of the operator's activity, who now does not directly control the movements of the UAV, leads to a change in the nature of the control system. One of the ways to solve this problem is to use an optical navigation system. The analysis of methods and algorithms for optical navigation of an unmanned aerial vehicle: algorithms for local navigation and cartography, correlation-extreme navigation methods and methods of visual odometry. The advantages and disadvantages of optical navigation methods are considered. The use of visual odometry methods has advantages over other meth- 
ods, but it also has disadvantages associated with the accumulation of errors in the course of the method. Variations of algorithms for simultaneous localization and mapping (SLAM) based on the use of cameras are called visual SLAM. The visual SLAM and visual odometry methods are analyzed. Hybrid SLAM methods solve the problem of error accumulation.

The use of UAVs for studying geological processes of the coastline of reservoirs and seas is analyzed. The advantages of using SLAM algorithms for monitoring the state of the coastline are considered. It is concluded that the use of SLAM algorithms for assessing the density of the erosion network of the coastline of reservoirs and seas makes it possible to obtain images without geometric distortions, an optical navigation system based on these algorithms greatly facilitates the operator's task, and will allow the UAV to be returned in case of loss of communication with the operator.

Keywords: optical navigation system, unmanned aerial vehicle, algorithms for local navigation and cartography, coastal monitoring.

\section{Відомості про авторів:}

Толкунова Юлія Миколаївна - к.т.н., доцент кафедри Систем управління літальними апаратами, Національний аерокосмічний університет ім. М.€. Жуковського «Харківський авіаційний інститут», Харків, Україна, y.tolkunova@khai.edu, ORCID 0000-0003-1081-9709.

Подколзіна Дарина Олександрівна - аспірант кафедри океанології, Південний федеральний університет, Ростов-на-Дону, Росія, Podkolzina@sfedu.ru.

\section{Сведения об авторах:}

Толкунова Юлия Николаевна - к.т.н., доцент кафедры Систем управления летательными аппаратами, Национальный аэрокосмический университет им. Н.Е. Жуковского «Харьковский авиационный институт», Харьков, Украина, y.tolkunova@khai.edu, ORCID 0000-0003-1081-9709.

Подколзина Дарина Александрова - аспирант кафедры океанологии, Южный федеральный университет, Ростов-на-Дону, Россия, Podkolzina@sfedu.ru.

\section{About the authors:}

Tolkunova Yulija - Ph.D, Associate Professor, Department of Aircraft Control Systems, National Aerospace University, M. Ye. Zhukovsky "Kharkiv Aviation Institute", Kharkiv, Ukraine, y.tolkunova@khai.edu, ORCID 0000-0003-1081-9709.

Podkolzina Darina - Post-graduate student, Department of Oceanology, Southern Federal University, Rostov-on-Don, Russia, Podkolzina@sfedu.ru. 